\title{
Can increased interoception explain exercise-induced benefits on brain function and cognitive performance?
}

Juan Antonio Zarza ${ }^{1}$, Daniel Sanabria ${ }^{1}$, Pandelis Perakakis ${ }^{2}$

\author{
${ }^{1}$ Mind, Brain, \& Behavior Research Center (CIMCYC), University of Granada, Spain; Department of \\ Experimental Psychology, University of Granada, Spain. \\ ${ }^{2}$ Mind, Brain, \& Behavior Research Center (CIMCYC), University of Granada, Spain; Department of \\ Psychology, Universidad Loyola Andalucía, Seville, Spain
}

\begin{abstract}
The benefits of regular physical exercise do not only concern physical wellness, but also seem to influence cognitive function. Multiple pathways have been suggested to explain the potential impact of regular exercise on cognition, from cellular, molecular and structural adaptations, to behavioral and social consequences of exercising). In this review, we propose interoception as a potential factor involved in the relationship between cognition and physical exercise. We first define and describe interoception, its dimensions and properties, to then, summarize the current research regarding interoception and cognition. Third, we examine the bidirectional role existing between interoception and physical activity. Finally, we lay out the evidence that leads us to consider the reciprocal relationship between exercise, cognition and interoception.
\end{abstract}

\section{Interoception}

Classically, cognitive neuroscience has focused mainly in understanding how the brain perceives and responds to external stimuli. In contrast, the processing and responses to internal sensations remain less understood, despite the existence of multiple theories highlighting their role in psychological processes such as emotion (James, 1894). Since Sherrington's first definition of interoceptors at the beginning of the last century (Sherrington CS, 1906), which included only visceral afferents received by the brain, interoception has been subject to various interpretations. Currently, interoception includes sensations such as pain and temperature, among other physiological signals from the entire body, which are eventually processed by the brain (Craig, 2002). The perception of these internal cues, varies not only between individuals, but also in the same person, depending on multiple factors, such as body composition, age, gender, etc. (Cameron, 2001). 
The ability to process interoceptive signals can be measured in three different dimensions: (1) interoceptive accuracy, evaluating performance on a behavioral task, e.g., heartbeat detection task, to evaluate participants' ability to detect their heartbeat, (2) interoceptive sensitivity, measured with questionnaires of self-perception of subjects' interoceptive accuracy, and (3) interoceptive awareness, the metacognition of one's own interoceptive aptitudes, i.e., a quotient between how precise a participant thinks his/her interoceptive ability is (i.e., interoceptive sensibility) and their actual ability (i.e., interoceptive accuracy) (Garfinkel, Seth, Barrett, Suzuki, \& Critchley, 2015). Although interoception has been studied in multiple axes (e.g., cardiac, respiratory, gastric, etc.), this review focuses on cardiac interoception.

Cardioceptive accuracy can be assessed either by behavioral tests or by a neurophysiological index, the heartbeat evoked potential (HEP). Particularly, there are two behavioral tasks that have dominated the relevant literature: heartbeat tracking, asking subjects to count their heartbeats silently in a determined time frame (Schandry, 1981), and heartbeat discrimination, asking subjects to determine if a series of stimuli are presented synchronously or asynchronously to their own heartbeats (Whitehead, Drescher, Heiman, \& Blackwell, 1977). As a more objective neural index of interoception, researchers have measured the HEP, defined as the cortical signal evoked by the heartbeat. The HEP can be regarded as an event-related potential (ERP) elicited by heartbeats, and it is measured by time-locking the EEG signal to particular spikes in the ECG waveform (most commonly the predominant R-wave spike) (Kern, Aertsen, Schulze-Bonhage, \& Ball, 2013; Schandry, Sparrer, \& Weitkunat, 1986). It presents large spatio-temporal variability, thus significant differences have been reported in different spatial clusters as well as different time windows, from 171 to 575 ms (see Petzschner et al., 2019 for a more detailed description). The HEP has been commonly used to measure cardioceptive accuracy, since it has been shown that its amplitude differs depending on the subjects' ability of perceiving their own heartbeat, correlating with previous self-reported measures, i.e. heartbeat detection tasks (Pollatos \& Schandry, 2004). There is a great significance in having a neurophysiological index of interoception exempt from the subjective intervention of the participant, due to the recently described limitations of the heartbeat detection tasks. For instance, prior beliefs have been reported to influence the outcome of these tasks (Windmann, Schonecke, Fröhlig, \& Maldener, 1999). Furthermore, Zamariola and colleagues found that interoceptive accuracy was influenced by variables independent of the participant's ability, such as the resting heart rate and the duration of the task (Zamariola, Maurage, Luminet, \& Corneille, 2018). 


\section{Interoception and cognition}

Apart from playing a crucial role in homeostatic regulation, interoceptive signals also appear to be related to cognitive processing. For instance, better detection of one's bodily signals seem to allow a greater knowledge of the different emotional states, thus enabling enhanced emotional regulation (Herbert, Pollatos, \& Schandry, 2007; Niedenthal, 2007; Wiens, Mezzacappa, \& Katkin, 2000). These findings are consistent with James-Lange's theory of emotion (James, 1894), according to which internal cues are essential for the origin of emotional responses, and with Damasio's 'somatic marker' hypothesis, sustaining that interoception has an important role on the origin of emotion, and consequently in the process of decision making (Damasio, 1996, 1999, 2003). In addition, interoceptive signals together with exteroceptive and sensorimotor signals - have been proposed to generate and modify self-consciousness and self-awareness (Blanke, 2012; Tsakiris, 2010), as well as modulate the ability of self-recognition (Tajadura-Jiménez \& Tsakiris, 2014; Tsakiris, Tajadura-Jiménez, \& Costantini, 2011). Increased self-attention, at the same time, enhances interoception awareness, showing evidence of a reciprocal association (Ainley, Maister, Brokfeld, Farmer, \& Tsakiris, 2013). Similarly, focusing attention on one's own heartbeats has recently been found to increase the magnitude of the HEP compared to focusing attention on an exteroceptive cue (Petzschner et al., 2019). Concerning perception, different studies have reported an association between interoceptive signals and the way visual or tactile signals are perceived (Aspell et al., 2013; Ronchi et al., 2017). Indeed, the amplitude of the HEP has been correlated with the ability to detect faint visual stimuli (Park, Correia, Ducorps, \& Tallon-Baudry, 2014).

\section{Modulation of interoception}

The difficulty of manipulating interoception, compared to exteroception, has been considered a limitation of this research (Tsakiris \& Critchley, 2016). Together with the objective of overcoming this limitation, the potential modulation of interoception has long been examined with the aim of enhancing the performance related to the aforementioned processes. Several approaches have been considered. Hassanpour and colleagues recently described a pharmacological methodology, through beta-adrenergic stimulation by intravenous infusion of isoprotenerol, to increase cardiorespiratory arousal, leading to an enhancement of interoceptive abilities (Hassanpour et al., 2016). Similarly, Schulz et. al reported increased HEP amplitude following cortisol administration (Schulz et al., 2013). The use of heartbeat feedback has also induced improvements in cardiac interoceptive accuracy, using auditory (Canales-Johnson et al., 2015; Schandry \& Weitkunat, 1990), tactile (Ring, 
Brener, Knapp, \& Mailloux, 2015) and visual feedback (Schaefer, Egloff, Gerlach, \& Witthöft, 2014). Notably, Canales-Johnson et al. observed an increase in HEP amplitude after feedback training in interoceptive-learners (those who showed improvement) compared to non-learners.

\section{The bidirectional relationship between interoception and physical exercise}

Physical exercise has been proposed as another factor closely related to the ability to process internal body signals. Indeed, there seems to be a bidirectional relationship between interoception and physical exercise, whereby interoception influences exercise performance and exercise performance induces changes in interoceptive processing. When we run, our central nervous system (CNS) makes possible every stride, sending efferent signals through the peripheral nervous system (PNS). Particularly, the somatic nervous system (SNS) is responsible for recruiting, in a selective manner, the required motor units to activate the appropriate muscles. On the other hand, the autonomic nervous system (ANS), through constant feedback, permits physiological adaptation as a function of exercise demands (Freeman, Dewey, Hadley, Myers, \& Froelicher, 2006; Freund, 1983; Huxley, 1969; Sherrington CS, 1906). Interoception provides the representation of the physiological condition of one's body in order to make possible this dynamic crosstalk between CNS and the periphery during exercise (Craig, 2002).

Recent studies have reported a relation between interoceptive abilities and physical performance, suggesting that interoception facilitates self-regulation during exercise (Georgiou et al., 2015; Herbert, Ulbrich, \& Schandry, 2007). For instance, Herbert and colleagues found that when subjects were free to set their own pace in a bicycle ergometer for a 15 minutes task, good heartbeat perceivers showed less heart rate, stroke volume and cardiac output, as well as a shorter tracked distance (Herbert, Ulbrich, et al., 2007). In this study, subjects with better interoceptive accuracy set a more bearable pace, regulating better their fatigue, in comparison with poor heartbeat perceivers. Georgiou and colleagues found that children with normal or high body mass index and higher interoceptive sensitivity covered a larger distance in a 6 minutes running performance task (Georgiou et al., 2015). In contrast, more recently, da Silva Machado and colleagues found no differences in maximal performance between a group of poor and good heartbeat perceivers (Machado et al., 2019).

The influence of interoception on exercise performance is more evident in precision sports, like shooting or archery. For instance, Keast and Elliot reported that shooting 
accuracy depends on the exact moment of the cardiac cycle when the shot is triggered (Keast \& Elliott, 1990). Helin and colleagues observed that athletes with better cardiac awareness (i.e., cardioceptive accuracy) were able to pull the trigger at the points of the cardiac cycle when higher accuracy is achieved, i.e. during ventricular diastole, because the heart provokes an almost imperceptible shake during the systole, which may affect the trajectory of the bullet (Helin, Sihvonen, \& Hänninen, 1987). Moreover, biofeedback performed in 8 junior experienced shooters resulted in greater awareness and led shooters to a better performance (Daniels \& Landers, 1981).

As noted above, there is also evidence that physical exercise can affect interoception. For instance, Jones and Hollandsworth showed that even a single session of exercise improved cardiac awareness on participants with average fitness (Jones \& Hollandsworth, 1981). Also, in that study, high fit males showed enhanced cardiac awareness in comparison with sedentary males both before and after exercise. Later, Mongomery and colleagues (Montgomery, Jones, \& Hollandsworth, 1984), replicated the enhanced heartbeat awareness assessed after physical activity in both groups of physical condition. However, they failed to demonstrate improved heartbeat perception in high fit subjects compared to low fit subjects at rest. Moreover, Antony and colleagues found differences in cardioceptive accuracy, measured using the heartbeat counting method, after short periods of exercise in 3 groups - social phobia, panic disorder and normal controlscompared to heartbeat perception at rest (Antony et al., 1995). No differences were found between groups either at rest or after exercise. Reported differences in heartbeat detection tasks between athletes and sedentary subjects have been suggested to have their origin in the increased stroke volume of athletes, a physiological adaptation provoked by regular exercise (Schandry, Bestler, \& Montoya, 1993). This heart adaptation would provide athletes with an advanced ability to perceive their own heartbeats. Although there are far less studies that refer to other dimensions of interoception, subjective methods to evaluate interoception after exercise have assessed, for example, ventilatory parameters. For instance, Faull and colleagues showed that endurance athletes reported an increased breathlessness-anxiety compared with their sedentary counterparts during a maximal effort, suggesting improved ventilatory perception (Faull, Cox, \& Pattinson, 2016).

All the studies described in this section are not exempt from the criticism described above with regard to the methods used to assess interoception. We believe future research should turn towards objective indexes of interoception, e.g., the HEP, combined with behavioral indexes to obtain a clearer picture of interoceptive abilities and their potential relationship with physical exercise. 


\section{Is interoception a potential mediator of the relationship between exercise and brain \& cognition?}

Regular physical exercise is thought to protect the brain from ageing and neurodegenerative diseases (Erickson et al., 2011; Hertzog, Kramer, Wilson, \& Lindenberger, 2008; Voss, Vivar, Kramer, \& van Praag, 2013), and to induce measurable changes at cognitive and brain levels (de Greeff, Bosker, Oosterlaan, Visscher, \& Hartman, 2018; Stillman, Cohen, Lehman, \& Erickson, 2016; although see the meta-analysis and systematic reviews that question these potential benefits; e.g., Singh et al., 2018; Verburgh, Königs, Scherder, \& Oosterlaan, 2014; Young, Angevaren, Rusted, \& Tabet, 2015). Assuming that there is a true effect of regular exercise on brain and cognition, the mechanisms underlying this effect are still a matter of scientific debate (Smith et al., 2010). Considering that interoception has been associated both with cognitive processing and physical exercise, and that physical exercise has been linked to cognitive and brain changes, it appears reasonable to hypothesize that physical exercise may affect cognition and brain functioning via its effect on interoception. Next, we summarize the evidence that would support the hypothesis of the involvement of interoception in the cognitive changes caused by physical exercise.

On the one hand, there is evidence for a common anatomic substrate involved in both, interoceptive processing and exercise performance. First, the anterior cingulate cortex and anterior insular cortex are selectively activated during acute exercise (Williamson, Fadel, \& Mitchell, 2006; Williamson, McColl, \& Mathews, 2003). Second, the insula receives visceral afferents from the autonomic system, which has been proposed as a factor involved in the representation of one's physiological condition, i.e., in interoceptive processes (Craig, 2002; Critchley, Wiens, Rotshtein, Ohman, \& Dolan, 2004; Singer, Critchley, \& Preuschoff, 2009). Third, the anterior cingulate cortex is closely related to the insula, being considered an output region for the interoceptive system (Medford \& Critchley, 2010). Fourth, the insular cortex is considered a hemodynamic control center, therefore having a key role in the brainheart communication, closely related to physiological regulation during exercise (Chouchou et al., 2019; Nagai, Hoshide, \& Kario, 2010; Oppenheimer, Gelb, Girvin, \& Hachinski, 1992; Ruggiero, Mraovitch, Granata, Anwar, \& Reis, 1987). Last, but not least, these hubs are connected with the dorsolateral prefrontal cortex, which presents a pivotal role in executive functioning (Bush, Luu, \& Posner, 2000; Carter, Botvinick, \& Cohen, 1999; Sridharan, Levitin, \& Menon, 2008). As a consequence, it seems reasonable, that inputs received by the insula determine the behavior and decisions taken during exercise, e.g., reduce the pace, accelerate or stop (McMorris, Barwood, \& Corbett, 2018). On the other hand, cognitive 
effects following the regular practice of physical exercise seem to be selective to executive functions (Colcombe \& Kramer, 2003; Kramer et al., 1999). Interestingly, the brain regions classically associated with interoception, i.e., the insular cortex and the anterior cingulate cortex, have also been linked to attention and executive-control (Heilbronner \& Hayden, 2016; Seeley et al., 2007).

Taken together, the above evidence suggests a potential key role of interoception in the mediation of the effects of physical exercise over cognition in general and executive function in particular. Physical activity requires constant afferent communication to the brain in order to cope with exercise demands. We suggest that this "training" in "listening" to our bodily signals leads to a better perception of our internal cues, i.e., interoceptive abilities (cf. Canales-Johnson et al., 2015). We propose that, as a consequence of the interoceptive improvements caused by the practice of regular exercise, executive functioning could also be enhanced. The overlap of neural structures, which are involved in both interoceptive processing and exercise, such as the insular cortex or the anterior cingulate cortex, supports our hypothesis. These improvements, which seem to be selective to the executive function, would (most likely) be observed in cohorts with a higher window of improvement, such as children, old people, or neurological patients. For this reason, although mechanisms underlying these effects remain unclear, it seems feasible to consider interoception as a potential mediator, among other factors (Stillman et al., 2016).

Even though, given our current knowledge, the interoceptive hypothesis seems highly plausible, it needs to be tested empirically. First, studies are required to understand the effects of a single bout of exercise on an objective marker of interoception, such as the HEP, and whether this correlates with cognitive performance. Then, exercise effects on HEP amplitude should be analysed in the long term, performing randomised controlled trials in order to understand the relationship between HEP, exercise and cognition, and analyse the mediation of HEP changes in exercise-induced cognitive alterations. 


\section{References}

Ainley, V., Maister, L., Brokfeld, J., Farmer, H., \& Tsakiris, M. (2013). More of myself: manipulating interoceptive awareness by heightened attention to bodily and narrative aspects of the self. Consciousness and Cognition, 22(4), 1231-1238. https://doi.org/10.1016/j.concog.2013.08.004

Antony, M. M., Brown, T. A., Craske, M. G., Barlow, D. H., Mitchell, W. B., \& Meadows, E. A. (1995). Accuracy of heartbeat perception in panic disorder, social phobia, and nonanxious subjects. J ournal of Anxiety Disorders, 9(5), 355-371. https://doi.org/10.1016/0887-6185(95)00017-I

Aspell, J. E., Heydrich, L., Marillier, G., Lavanchy, T., Herbelin, B., \& Blanke, O. (2013). Turning Body and Self Inside Out: Visualized Heartbeats Alter Bodily SelfConsciousness and Tactile Perception. Psychological Science, 24(12), 2445-2453. https://doi.org/10.1177/0956797613498395

Blanke, O. (2012). Multisensory brain mechanisms of bodily self-consciousness. Nature Reviews Neuroscience. https://doi.org/10.1038/nrn3292

Bush, G., Luu, P., \& Posner, MI. (2000). Cognitive and emotional influences in anterior cingulate cortex. Trends in Cognitive Sciences, 4(6), 215-222.

Cameron, O. G. (2001). Interoception: the inside story--a model for psychosomatic processes. Psychosomatic Medicine, 63(5), 697-710.

Canales-Johnson, A., Silva, C., Huepe, D., Rivera-Rei, Á., Noreika, V., Garcia, M. del C., ... Bekinschtein, T. A. (2015). Auditory Feedback Differentially Modulates Behavioral and Neural Markers of Objective and Subjective Performance When Tapping to Your Heartbeat. Cerebral Cortex, 25(11), 4490-4503.

https://doi.org/10.1093/cercor/bhv076

Carter, C. S., Botvinick, M. M., \& Cohen, J. D. (1999). The contribution of the anterior cingulate cortex to executive processes in cognition. Reviews in the Neurosciences, 10(1), 49-57. 
Chouchou, F., Mauguière, F., Vallayer, O., Catenoix, H., Isnard, J., Montavont, A., ... Mazzola, L. (2019). How the insula speaks to the heart: Cardiac responses to insular stimulation in humans. Human Brain Mapping. https://doi.org/10.1002/hbm.24548

Colcombe, S., \& Kramer, A. F. (2003). Fitness effects on the cognitive function of older adults: a meta-analytic study. Psychological Science, 14(2), 125-130. https://doi.org/10.1111/1467-9280.t01-1-01430

Craig, A. D. (2002). How do you feel? Interoception: the sense of the physiological condition of the body. Nature Reviews. Neuroscience, 3(8), 655-666. https://doi.org/10.1038/nrn894

Critchley, H. D., Wiens, S., Rotshtein, P., Ohman, A., \& Dolan, R. J. (2004). Neural systems supporting interoceptive awareness. Nature Neuroscience, 7(2), 189-195. https://doi.org/10.1038/nn1176

Damasio, A. R. (1996). The somatic marker hypothesis and the possible functions of the prefrontal cortex. Philosophical Transactions of the R oyal Society of London. Series B, Biological Sciences, 351(1346), 1413-1420. https://doi.org/10.1098/rstb.1996.0125

Damasio, A. R. (1999). The Feeling of What Happens: Body and Emotion in the Making of Consciousness. New York: Harcourt, Brace \& Company.

Damasio, A. R. (2003). Feelings of emotion and the self. Annals of the New York Academy of Sciences, 1001, 253-261.

Daniels, F. S., \& Landers, D. M. (1981). Biofeedback and Shooting Performance: A Test of Disregulation and Systems Theory. J ournal of Sport P sychology, 3(4), 271-282. https://doi.org/10.1123/jsp.3.4.271

de Greeff, J. W., Bosker, R. J., Oosterlaan, J., Visscher, C., \& Hartman, E. (2018). Effects of physical activity on executive functions, attention and academic performance in preadolescent children: a meta-analysis. J ournal of Science and Medicine in Sport, 21(5), 501-507. https://doi.org/10.1016/j.jsams.2017.09.595

Erickson, K. I., Voss, M. W., Prakash, R. S., Basak, C., Szabo, A., Chaddock, L., ... Kramer, A. F. (2011). Exercise training increases size of hippocampus and improves memory. 
Proceedings of the National Academy of Sciences of the United States of America, 108(7), 3017-3022. https://doi.org/10.1073/pnas.1015950108

Faull, O. K., Cox, P. J., \& Pattinson, K. T. S. (2016). Psychophysical Differences in Ventilatory Awareness and Breathlessness between Athletes and Sedentary Individuals. Frontiers in Physiology, 7. https://doi.org/10.3389/fphys.2016.00231

Freeman, J. V., Dewey, F. E., Hadley, D. M., Myers, J., \& Froelicher, V. F. (2006).

Autonomic Nervous System Interaction With the Cardiovascular System During Exercise. Progress in Cardiovascular Diseases, 48(5), 342-362.

https://doi.org/10.1016/j.pcad.2005.11.003

Freund, H. J. (1983). Motor unit and muscle activity in voluntary motor control. Physiological Reviews, 63(2), 387-436.

Garfinkel, S. N., Seth, A. K., Barrett, A. B., Suzuki, K., \& Critchley, H. D. (2015). Knowing your own heart: Distinguishing interoceptive accuracy from interoceptive awareness. Biological P sychology, 104, 65-74. https://doi.org/10.1016/j.biopsycho.2014.11.004

Georgiou, E., Matthias, E., Kobel, S., Kettner, S., Dreyhaupt, J., Steinacker, J. M., \& Pollatos, O. (2015). Interaction of physical activity and interoception in children. Frontiers in Psychology, 6. https://doi.org/10.3389/fpsyg.2015.00502

Hassanpour, M. S., Yan, L., Wang, D. J. J., Lapidus, R. C., Arevian, A. C., Simmons, W. K., ... Khalsa, S. S. (2016). How the heart speaks to the brain: neural activity during cardiorespiratory interoceptive stimulation. Philosophical Transactions of the Royal Society of London. Series B, Biological Sciences, 371(1708). https://doi.org/10.1098/rstb.2016.0017

Heilbronner, S. R., \& Hayden, B. Y. (2016). Dorsal Anterior Cingulate Cortex: A Bottom-Up View. Annual Review of Neuroscience, 39, 149-170. https://doi.org/10.1146/annurevneuro-070815-013952

Helin, P., Sihvonen, T., \& Hänninen, O. (1987). Timing of the triggering action of shooting in relation to the cardiac cycle. British J ournal of Sports Medicine, 21(1), 33-36. 
Herbert, B. M., Pollatos, O., \& Schandry, R. (2007). Interoceptive sensitivity and emotion processing: An EEG study. International J ournal of P sychophysiology, 65(3), 214227. https://doi.org/10.1016/j.jpsycho.2007.04.007

Herbert, B. M., Ulbrich, P., \& Schandry, R. (2007). Interoceptive sensitivity and physical effort: implications for the self-control of physical load in everyday life. Psychophysiology, 44(2), 194-202. https://doi.org/10.1111/j.1469-8986.2007.00493.x Hertzog, C., Kramer, A. F., Wilson, R. S., \& Lindenberger, U. (2008). Enrichment Effects on Adult Cognitive Development: Can the Functional Capacity of Older Adults Be Preserved and Enhanced? Psychological Science in the Public Interest, 9(1), 1-65. https://doi.org/10.1111/j.1539-6053.2009.01034.x

Huxley, H. E. (1969). The mechanism of muscular contraction. Science (New York, N.Y.), 164(3886), 1356-1365.

James, W. (1894). The physical bases of emotion. 1894. P sychological R eview, 101(2), 205210.

Jones, G. E., \& Hollandsworth, J. G. (1981). Heart Rate Discrimination Before and After Exercise-Induced Augmented Cardiac Activity. Psychophysiology, 18(3), 252-257. https://doi.org/10.1111/j.1469-8986.1981.tb03029.x

Keast, D., \& Elliott, B. (1990). Fine body movements and the cardiac cycle in archery. J ournal of S ports Sciences, 8(3), 203-213. https://doi.org/10.1080/02640419008732146

Kern, M., Aertsen, A., Schulze-Bonhage, A., \& Ball, T. (2013). Heart cycle-related effects on event-related potentials, spectral power changes, and connectivity patterns in the human ECoG. Neurolmage, 81, 178-190. https://doi.org/10.1016/j.neuroimage.2013.05.042

Kramer, A. F., Hahn, S., Cohen, N. J., Banich, M. T., McAuley, E., Harrison, C. R., ... Colcombe, A. (1999). Ageing, fitness and neurocognitive function. Nature, 400(6743), 418-419. https://doi.org/10.1038/22682 
Machado, D. G. da S., Farias Junior, L. F. de, Nascimento, P. H. D. do, Tavares, M. P. M., Anselmo da Silva, S. K., Agrícola, P. M. D., ... Okano, A. H. (2019). Can interoceptive accuracy influence maximal performance, physiological and perceptual responses to exercise? Physiology \& Behavior, 204, 234-240.

https://doi.org/10.1016/j.physbeh.2019.02.038

McMorris, T., Barwood, M., \& Corbett, J. (2018). Central fatigue theory and endurance exercise: Toward an interoceptive model. Neuroscience and Biobehavioral Reviews. https://doi.org/10.1016/j.neubiorev.2018.03.024

Medford, N., \& Critchley, H. D. (2010). Conjoint activity of anterior insular and anterior cingulate cortex: awareness and response. Brain Structure \& Function, 214(5-6), 535-549. https://doi.org/10.1007/s00429-010-0265-x

Montgomery, W. A., Jones, G. E., \& Hollandsworth, J. G. (1984). The effects of physical fitness and exercise on cardiac awareness. Biological Psychology, 18(1), 11-22.

Nagai, M., Hoshide, S., \& Kario, K. (2010). The insular cortex and cardiovascular system: a new insight into the brain-heart axis. J ournal of the American Society of Hypertension: J ASH, 4(4), 174-182. https://doi.org/10.1016/j.jash.2010.05.001

Niedenthal, P. M. (2007). Embodying Emotion. Science, 316(5827), 1002-1005. https://doi.org/10.1126/science.1136930

Oppenheimer, S. M., Gelb, A., Girvin, J. P., \& Hachinski, V. C. (1992). Cardiovascular effects of human insular cortex stimulation. Neurology, 42(9), 1727-1732.

Park, H.-D., Correia, S., Ducorps, A., \& Tallon-Baudry, C. (2014). Spontaneous fluctuations in neural responses to heartbeats predict visual detection. Nature Neuroscience, 17(4), 612-618. https://doi.org/10.1038/nn.3671

Petzschner, F. H., Weber, L. A., Wellstein, K. V., Paolini, G., Do, C. T., \& Stephan, K. E. (2019). Focus of attention modulates the heartbeat evoked potential. Neurolmage, 186, 595-606. https://doi.org/10.1016/j.neuroimage.2018.11.037

Pollatos, O., \& Schandry, R. (2004). Accuracy of heartbeat perception is reflected in the amplitude of the heartbeat-evoked brain potential: Heartbeat-evoked potential and 
heartbeat perception. Psychophysiology, 41(3), 476-482.

https://doi.org/10.1111/1469-8986.2004.00170.x

Ring, C., Brener, J., Knapp, K., \& Mailloux, J. (2015). Effects of heartbeat feedback on beliefs about heart rate and heartbeat counting: a cautionary tale about interoceptive awareness. Biological Psychology, 104, 193-198. https://doi.org/10.1016/j.biopsycho.2014.12.010

Ronchi, R., Bernasconi, F., Pfeiffer, C., Bello-Ruiz, J., Kaliuzhna, M., \& Blanke, O. (2017). Interoceptive signals impact visual processing: Cardiac modulation of visual body perception. Neurolmage, 158, 176-185. https://doi.org/10.1016/j.neuroimage.2017.06.064

Ruggiero, D. A., Mraovitch, S., Granata, A. R., Anwar, M., \& Reis, D. J. (1987). A role of insular cortex in cardiovascular function. The J ournal of Comparative Neurology, 257(2), 189-207. https://doi.org/10.1002/cne.902570206

Schaefer, M., Egloff, B., Gerlach, A. L., \& Witthöft, M. (2014). Improving heartbeat perception in patients with medically unexplained symptoms reduces symptom distress. Biological Psychology, 101, 69-76. https://doi.org/10.1016/j.biopsycho.2014.05.012

Schandry, R. (1981). Heart beat perception and emotional experience. Psychophysiology, 18(4), 483-488.

Schandry, R., Bestler, M., \& Montoya, P. (1993). On the relation between cardiodynamics and heartbeat perception. Psychophysiology, 30(5), 467-474.

Schandry, R., Sparrer, B., \& Weitkunat, R. (1986). From the heart to the brain: A study of heartbeat contingent scalp potentials. International J ournal of Neuroscience, 30(4), 261-275. https://doi.org/10.3109/00207458608985677

Schandry, R., \& Weitkunat, R. (1990). Enhancement of heartbeat-related brain potentials through cardiac awareness training. The International J ournal of Neuroscience, 53(24), 243-253. 
Schulz, A., Strelzyk, F., Ferreira de Sá, D. S., Naumann, E., Vögele, C., \& Schächinger, H. (2013). Cortisol rapidly affects amplitudes of heartbeat-evoked brain potentialsImplications for the contribution of stress to an altered perception of physical sensations? P sychoneuroendocrinology, 38(11), 2686-2693.

https://doi.org/10.1016/j.psyneuen.2013.06.027

Seeley, W. W., Menon, V., Schatzberg, A. F., Keller, J., Glover, G. H., Kenna, H., ... Greicius, M. D. (2007). Dissociable intrinsic connectivity networks for salience processing and executive control. The J ournal of Neuroscience: The Official J ournal of the Society for Neuroscience, 27(9), 2349-2356. https://doi.org/10.1523/JNEUROSCI.5587-06.2007

Sherrington CS. (1906). The integrative action of the nervous system. New Haven, CT: Yale University Press.

Singer, T., Critchley, H. D., \& Preuschoff, K. (2009). A common role of insula in feelings, empathy and uncertainty. Trends in Cognitive Sciences, 13(8), 334-340. https://doi.org/10.1016/j.tics.2009.05.001

Singh, A. S., Saliasi, E., van den Berg, V., Uijtdewilligen, L., de Groot, R. H. M., Jolles, J., ... Chinapaw, M. J. M. (2018). Effects of physical activity interventions on cognitive and academic performance in children and adolescents: a novel combination of a systematic review and recommendations from an expert panel. British J ournal of Sports Medicine, bjsports-2017-098136. https://doi.org/10.1136/bjsports-2017098136

Smith, P. J., Blumenthal, J. A., Hoffman, B. M., Cooper, H., Strauman, T. A., Welsh-Bohmer, K., ... Sherwood, A. (2010). Aerobic Exercise and Neurocognitive Performance: A Meta-Analytic Review of Randomized Controlled Trials: Psychosomatic Medicine, 72(3), 239-252. https://doi.org/10.1097/PSY.0b013e3181d14633

Sridharan, D., Levitin, D. J., \& Menon, V. (2008). A critical role for the right fronto-insular cortex in switching between central-executive and default-mode networks. 
Proceedings of the National Academy of Sciences of the United States of America, 105(34), 12569-12574. https://doi.org/10.1073/pnas.0800005105

Stillman, C. M., Cohen, J., Lehman, M. E., \& Erickson, K. I. (2016). Mediators of Physical Activity on Neurocognitive Function: A Review at Multiple Levels of Analysis. Frontiers in Human Neuroscience, 10. https://doi.org/10.3389/fnhum.2016.00626

Tajadura-Jiménez, A., \& Tsakiris, M. (2014). Balancing the «inner» and the «outer» self: interoceptive sensitivity modulates self-other boundaries. J ournal of Experimental Psychology. General, 143(2), 736-744. https://doi.org/10.1037/a0033171

Tsakiris, M. (2010). My body in the brain: a neurocognitive model of body-ownership. Neuropsychologia, 48(3), 703-712. https://doi.org/10.1016/j.neuropsychologia.2009.09.034

Tsakiris, M., \& Critchley, H. (2016). Interoception beyond homeostasis: affect, cognition and mental health. Philosophical Transactions of the R oyal Society B: Biological Sciences, 371(1708), 20160002. https://doi.org/10.1098/rstb.2016.0002

Tsakiris, M., Tajadura-Jiménez, A., \& Costantini, M. (2011). Just a heartbeat away from one's body: interoceptive sensitivity predicts malleability of body-representations. Proceedings. Biological Sciences, 278(1717), 2470-2476. https://doi.org/10.1098/rspb.2010.2547

Verburgh, L., Königs, M., Scherder, E. J. A., \& Oosterlaan, J. (2014). Physical exercise and executive functions in preadolescent children, adolescents and young adults: a metaanalysis. British J ournal of Sports Medicine, 48(12), 973-979. https://doi.org/10.1136/bjsports-2012-091441

Voss, M. W., Vivar, C., Kramer, A. F., \& van Praag, H. (2013). Bridging animal and human models of exercise-induced brain plasticity. Trends in Cognitive Sciences, 17(10), 525-544. https://doi.org/10.1016/j.tics.2013.08.001

Whitehead, W. E., Drescher, V. M., Heiman, P., \& Blackwell, B. (1977). Relation of heart rate control to heartbeat perception. Biofeedback and Self-Regulation, 2(4), 317-392. 
Wiens, S., Mezzacappa, E. S., \& Katkin, E. S. (2000). Heartbeat detection and the experience of emotions. Cognition \& E motion, 14(3), 417-427. https://doi.org/10.1080/026999300378905

Williamson, J. W., Fadel, P. J., \& Mitchell, J. H. (2006). New insights into central cardiovascular control during exercise in humans: a central command update. Experimental Physiology, 91(1), 51-58. https://doi.org/10.1113/expphysiol.2005.032037

Williamson, J. W., McColl, R., \& Mathews, D. (2003). Evidence for central command activation of the human insular cortex during exercise. J ournal of Applied Physiology (Bethesda, Md.: 1985), 94(5), 1726-1734. https://doi.org/10.1152/japplphysiol.01152.2002

Windmann, S., Schonecke, O. W., Fröhlig, G., \& Maldener, G. (1999). Dissociating beliefs about heart rates and actual heart rates in patients with cardiac pacemakers. Psychophysiology, 36(3), 339-342.

Young, J., Angevaren, M., Rusted, J., \& Tabet, N. (2015). Aerobic exercise to improve cognitive function in older people without known cognitive impairment. The Cochrane Database of Systematic Reviews, (4), CD005381. https://doi.org/10.1002/14651858.CD005381.pub4

Zamariola, G., Maurage, P., Luminet, O., \& Corneille, O. (2018). Interoceptive accuracy scores from the heartbeat counting task are problematic: Evidence from simple bivariate correlations. Biological P sychology, 137, 12-17. https://doi.org/10.1016/j.biopsycho.2018.06.006 